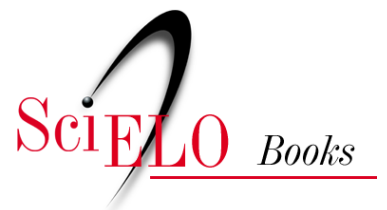

\title{
EDUFU
}

\section{Letramentos acadêmicos avanços e críticas recentes}

Brian Street

\section{SciELO Books / SciELO Livros / SciELO Libros}

STREET, B. Letramentos acadêmicos: avanços e críticas recentes. In: AGUSTINI, C., and ERNESTO, B., eds. Incursões na escrita acadêmico-universitária: letramento, discurso, enunciação [online]. Uberlândia: EDUFU, 2017, pp. 21-33. ISBN: 978-65-86084-26-9. https://doi.org/10.7476/9786586084269.0002.

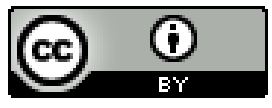

All the contents of this work, except where otherwise noted, is licensed under a Creative Commons Attribution 4.0 International license.

Todo o conteúdo deste trabalho, exceto quando houver ressalva, é publicado sob a licença Creative Commons Atribição 4.0. 


\section{Letramentos acadêmicos: avanços e críticas recentes ${ }^{1}$}

Brian Street ${ }^{2}$

\section{Abordagem de letramento acadêmico}

O estudo etnográfico de práticas de letramento acadêmico relatadas por Lea e Street (1998) chamou consideravelmente a atenção para a área dos estudos sobre letramento e dos estudos no âmbito do ensino superior. Curiosamente, os artigos de 1998 ainda são citados como os mais frequentemente mencionados na revista Studies in Higher Education. Baseados numa pesquisa realizada com algumas universidades inglesas, Mary Lea e eu propusemos três modelos que deveriam ser sustentados pelos profissionais da universidade participante no que concerne à redação dos alunos: habilidades de estudo, socialização acadêmica e letramento acadêmico.

Particularmente, à época das pesquisas, predominava fortemente, tanto na teoria, quanto na prática, o modelo de "habilidades de estudo". Todavia, como esse artigo demonstrou, e conforme reforçado e desenvolvido por estudos posteriores, a realidade - na prática - é de que há exigências múltiplas para que o aluno escreva de acordo

\footnotetext{
${ }^{1}$ Tradução de Stéfano Paschoal

${ }^{2}$ Agradecemos a Mary Lea pela coautoria do artigo original intitulado "Academic Literacies 15 years on", com algumas de suas partes reproduzidas aqui.
} 


\section{Brian Street}

com o contexto, variando conforme a disciplina, mas, também, dentre outras coisas, conforme as pressões institucionais, incluindo questões de financiamento bem como o papel dos tutores da disciplina, e não apenas dos estudantes.

Descrevemos isso como o modelo de "socialização acadêmica", que buscou levar em conta algumas dessas questões ao "integrar socialmente" os alunos no tocante às exigências acadêmicas. Entretanto, passamos a discutir sobre a necessidade de ampliarmos nosso entendimento e nossa prática nesse âmbito e, então, descrevemos este terceiro modelo, intitulado "Letramento Acadêmico" (doravante LA).

O LA exige dos pesquisadores que investiguem e, dos que lidam com a prática, que considerem a variedade evidente de práticas de Letramento Acadêmico em contextos específicos, concebendo o letramento como Prática Social nos últimos anos (cf. Gee, J. P., 1990; Lankshear, C e Knobel, M 2003; Collin, R. e Street, B. (a ser publicado); Street, B. 2005; 2012).

A abordagem da prática social para a escrita acadêmica inclui, para aqueles que trabalham no contexto acadêmico, ajustar novos e variados gêneros de escrita, diferentes exigências em termos de argumentação, estruturação de informações e estilos retóricos, bem como diferentes preferências dos professores. Tal variação e complexidade significaram que os dois modelos que muito provavelmente dominariam esta área, - habilidades de estudo e socialização acadêmica - não obstante tendo nos proporcionado um ponto de partida útil (cf. Wingate, 2015), foram concebidos de forma muito limitada para abarcar a gama de necessidades, exigências e práticas acerca do exercício de escrita na universidade.

\section{Avanços e críticas recentes}

Publicações atuais desenvolveram e ampliaram as descobertas e teorizações originais no artigo de $1998^{3}$ (Blommaert et al., 2008). Além disso, há relações interessantes a serem estabelecidas com o trabalho em áreas similares em diferentes países, especialmente no Reino Unido e nos Estados Unidos e, mais recentemente, também na França. 0 trabalho recente no Brasil - com a expansão das universidades - também tem se desenvolvido e se referido a diversas questões levantadas em outros lugares. Transmitirei brevemente minha própria experiência com essas questões nos últimos anos.

${ }^{3} \mathrm{O}$ autor se refere, aqui, ao artigo escrito por ele e Lea em 1998. 
Nos Estados Unidos, termos como "Escrita no âmbito das disciplinas/dos currículos", bem como gênero (cf. Russell et al., 2009) têm sido dignos de nota. Tanto nos Estados Unidos quanto no Reino Unido, o conceito de Inglês para Fins Acadêmicos (ESP) tem sido o foco de muitos pesquisadores e professores interessados no papel da língua inglesa em ambientes acadêmicos (p. ex., Wingate e Tribble, 2012). Na França, o trabalho de retórica e gênero abrange a questão da escrita na universidade (cf. Castelló e Donahue, 2012), Delcambre, I. \& Reuter, Y. (2010) têm feito relações, na França, sobre didática, com os campos assinalados aqui; da mesma forma, Donahue, T. (2009) que relaciona "Gênero e trabalho disciplinar" em pesquisas sobre didática na França; e Delcambre, I. \& Donahue, C. (2011, autores que têm observado os letramentos acadêmicos de universitários franceses. No Reino Unido, têm havido algumas contestações a alguns dos conceitos iniciais desenvolvidos por mim e por Mary Lea. Neste artigo, indicarei brevemente alguns desses avanços e críticas recentes.

\section{Críticas no Reino Unido}

No Reino Unido, Lillis e Scott (2007) têm discutido que a adesão a uma abordagem de letramento acadêmico envolve reconhecer a necessidade de transformação - e não de mera reprodução - das formas padronizadas correntes de leitura e escrita. Em conformidade com nosso artigo de 1998, eu e Mary Lea não concordamos completamente com essa abordagem. Certamente, ao discutir o fato de que a abordagem LA (letramento acadêmico) exige uma mudança sobre como se conceitua o auxílio à escrita, afastando-se, por exemplo, do modelo "deficitário" e aproximando-se bem mais de práticas variadas de letramento associadas a diferentes disciplinas e contextos em educação, nós não necessariamente a veríamos como uma mudança que envolve um desafio político dessa natureza às instituições, como parecem sugerir Scott e Lillis.

Pode ser, por exemplo, que alunos e professores reconheçam os gêneros ou estilos específicos de letramento necessários em determinado nível e aprendam a trabalhar com isto, mais do que tentarem subjugálo - "reflexão crítica" mais do que a tentativa de "transformar" práticas correntes, nos termos de Scott e Lillis. 


\section{Brian Street}

Percebemos, por um lado, uma diferença sutil entre tornar visíveis aspectos de poder e de autoridade e como esses aspectos estão incorporados nas práticas de letramento e, por outro, a noção de transformação. Enquanto, seguramente, interessados em como a universidade poderia transformar tais práticas e, interessados, também, na importância, por exemplo, de se contestarem formas de gênero e formas hierárquicas de práticas de conhecimento e de se contestarem, ainda, os processos através dos quais os estudantes são excluídos, consideramos a abordagem LA, tanto do ponto de vista da pesquisa, quanto da prática, como algo talvez mais etnográfico e menos político, na medida em que auxilia os participantes a perceberem e conceitualizarem o que de fato ocorre mais claramente como uma base para suas próprias atividades.

Tal consciência, então estendida, poderia envolver uma participação mais consciente nas práticas de escrita acadêmica ou contestar as formas dominantes com que são interpretadas, dependendo do contexto e dos interesses dos participantes.

Como este campo de pesquisa ainda está em desenvolvimento, novas vertentes e orientações estão constantemente surgindo. Embora quiséssemos nos manter fieis ao sentido original - usado por nós - do termo "letramento acadêmico", tal qual se vê no artigo de 1998, Mary Lea e eu temos perfeita consciência de que aqueles que trabalham diretamente com os estudantes, especialmente, têm usado o termo com diferentes acepções. Coffin e Donohue (2012), por exemplo, no tocante ao enfoque de características textuais e ao ensino de "letramento acadêmico", e Wingate e Tribble (2012), contestaram o que consideram uma dicotomia aparente entre "transformacional" e "normativo", baseados principalmente em sua leitura de Scott e Lillis (2008). Esses autores discutiram sobre o "melhor de ambos os mundos". Eles também apresentaram uma explicação mais positiva da atividade principal, incluindo habilidades de estudo e de socialização acadêmica, como a importância do foco em habilidades linguísticas e características textuais às quais os alunos deveriam se dedicar.

Na tentativa de alcançar "o melhor de ambos os mundos", eles lançaram mão de três abordagens para o ensino da escrita e teorias subjacentes: Letramento acadêmico, Inglês para Fins Acadêmicos e Linguística Sistêmico-Funcional. Todas elas contribuíram com princípios úteis. Entretanto, eu ainda aproveitaria os princípios estabelecidos 
no artigo escrito com Mary Lea e agiria de forma crítica em relação a quaisquer perspectivas que sugiram que os professores se remetam ao modelo de "habilidades de estudo" sem qualquer crítica.

No tocante a tópicos sobre língua, por exemplo, a abordagem tradicional de Inglês para Fins Acadêmicos ainda - eu diria - enfatiza muito fortemente o nível de habilidades e, no caso da língua, as características formais e padronizadas do inglês. De fato, o trabalho recente sobre multilinguismo e diversidade reconhece haver várias "línguas inglesas", assim como a abordagem LA mostra que há diversos letramentos.

Leung $(2008,2010)$, por exemplo, estendeu os argumentos principais na abordagem do letramento acadêmico para criar relações entre os diferentes expedientes separados até agora no âmbito profissional e o ensino de língua inglesa e, durante o processo, (re)inseriu a "língua" nas discussões sobre o letramento. Leung e Street (2012), com base num projeto financiado pelo Economic and Social Research Council (ESRC), estenderam esta abordagem à educação de nível escolar e investigaram de forma mais extensa a língua e as práticas de letramento no currículo. Utilizando-se de dados coletados de ambientes escolares londrinos, diversos em termos etnolinguísticos, eles analisam criticamente algumas das estruturas conceituais e teóricas em letramento e educação linguística "com o intuito de enriquecer e tornar mais complexos os pressupostos sobre os quais a compreensão desta diversidade pode se basear".

Procuram mostrar, ainda, como a "diversidade cotidiana e mundana e a heterogeneidade de contextos locais singulares podem permanecer dúbias tanto para os que as praticam, quanto para os que as planejam". A prática de língua e a prática de letramento podem ser dúbias no novo mundo globalizado e diverso, e apenas a combinação das abordagens de LA com o Inglês como Língua Internacional (ILI) podem ajudar os praticantes e os pesquisadores a lidar com esta complexidade (cf. também Blommaert, 2005 a respeito da sobrediversidade).

\section{Algumas abordagens nos Estados Unidos}

A relação das abordagens de LA ao trabalho nos Estados Unidos talvez seja bem mais complexa, uma vez que tem havido ali há muito mais tempo discussões sobre a escrita estudantil e o auxílio no ensino superior. 0 surgimento mais recente da "participação ampliada" na 


\section{Brian Street}

educação superior nos Estados Unidos levou à uma pesquisa relevante e à adaptação às práticas institucionais com o intuito de auxiliar a escrita estudantil, particularmente representada por abordagens como Escrita no âmbito das Disciplinas, Escrita no âmbito dos Currículos, Retórica, Gênero e Redação Acadêmica.

Entretanto, essas abordagens, ao contrário da perspectiva da abordagem LA no Reino Unido, não levaram tanto em consideração o equilíbrio entre o genérico e o específico e a significação de práticas variadas e perspectivas transformativas. Colegas nesses países e no âmago dessas tradições têm discutido essas questões atualmente, como se mostra evidente em muitas publicações recentes e relatos feitos em eventos acadêmicos.

Um artigo (Russell et al., 2009), escrito em coautoria por colegas de ambos os países, procura esboçar alguns elementos de cada país em relação ao outro e ao gênero, de forma especial. "À primeira vista", os autores reconhecem, "os dois países parecem ser bem diferentes. Cada um tem suas próprias tradições teóricas locais e metodológicas, e cada um implementa seus próprios termos: por exemplo, 'como sugerem seus respectivos títulos, um trata de redação, enquanto outro trata de letramento". Dessa forma, o diálogo futuro "pode prosseguir com muitas questões e congruências, mas com um cuidado acadêmico que se pode denominar saudável".

\section{Contribuição à prática}

Uma crítica à abordagem LA é que sua base é muito mais teórica e que não contribui com a prática. Eu prefiro contestar isto e fornecer aqui alguns exemplos de programas com os quais estive envolvido, trabalhando na King's College em Londres, na Universidade da Pensilvânia, nos Estados Unidos e na UFMG, no Brasil. Eu gostaria de discutir que a experiência nesses lugares, bem como em outros contextos, demonstra que a abordagem LA contribui, de facto, com a prática. Começarei com o debate político mais amplo que se voltou à aprendizagem de letramento em avaliações estatísticas estreitas e que fracassou ao não considerar as práticas locais de letramento de forma apropriada no contexto educacional. 


\section{"O enigma das graduações no Reino Unido e seu letramento de baixo nível"}

Um artigo discorrendo sobre "O enigma das graduações no Reino Unido e seu letramento de baixo nível" (Thes 11 Sept 2014) recorreu à avaliação de indicadores de performance como uma explanação possível para o que os autores apresentaram como "o enigma do letramento de baixo nível" entre os estudantes universitários do Reino Unido.

Os testes pareceram mostrar que esses estudantes não apresentavam um desempenho muito alto se comparados internacionalmente no âmbito de habilidades de letramento. Contestei essa abordagem relembrando que, recentemente, tornamo-nos cientes, no tocante à alfabetização de adultos, de que os índices de avaliações internacionais, tais como o Programa Internacional de Avaliação de Alunos (PISA) e o Programa para Avaliação Internacional das Competências dos Adultos (PIAAC) etc., não nos informam sobre os usos reais de leitura e escrita na vida cotidiana (Rogers e Street, 2012). Os testes podem avaliar quantitativamente as pessoas de modo a conduzir ao "enigma" relatado aqui, enquanto, em seu cotidiano, elas lidam com as práticas de letramento de forma perfeitamente adequada (Street, 2014). Sugeri que "talvez fosse o teste, e não os adultos, o enigma".

Uma perspectiva etnográfica sobre práticas de letramento permitenos remeter a essas questões, quando estudamos e analisamos os usos de tais práticas no cotidiano das pessoas, dentro de um país ou em vários países, sem cair na avaliação e confusão evidentes nessas pesquisas de cunho estatístico.

Assim, no contexto do Reino Unido, e aplicando esses debates aos estudantes ingressantes na universidade, a questão pode não ser o "baixo nível de letramento", mas, mais do que isso, as questões mais complexas associadas a como os estudantes aprendem a lidar com os diferentes gêneros e diferentes exigências de escrita no ensino superior. Pesquisadores estão frequentemente aplicando as perspectivas etnográficas mais que as estatísticas a esses processos, e disso resulta que referir-se ao "letramento acadêmico " (cf. Street, a ser publicado) de estudantes pode ser um caminho mais fértil do que a confusão acerca dos supostos "baixos níveis de letramento". 
Nas "entrelinhas" dos programas e disciplinas de escrita acadêmica na Universidade da Pensilvânia

Ministro regularmente um curso no programa de pós-graduação em Educação na Universidade da Pensilvânia e, em 2009, apresentei a ideia da abordagem LA a alguns estudantes que estavam na transição entre a graduação e cursos preparatórios que os levariam a ingressar no programa de doutorado. À primeira vista, eles estavam aparentemente bem afinados com as exigências de escrita da universidade, tendo obtido pelo menos uma graduação e, muitos, um mestrado. Todavia, à medida que aprofundamos as exigências com que estavam se deparando para escrever no nível em que passavam a ocupar, ficou evidente que eles teriam de aprender novos letramentos acadêmicos, os quais passamos a nos referir como "letramentos ocultos" (Street, 2009).

Enquanto os tutores e a instituição explicitavam as demandas referentes às características abertas deste tipo de escrita, geralmente através de listas pré-concebidas de coisas a serem abarcadas, como, por exemplo, a estrutura de um ensaio (i.e., introdução, teoria, métodos), nós, à luz da abordagem LA, rapidamente percebemos que o exigido nas avaliações de escrita acadêmica, muitas vezes, permanecia implícito. A isso é que demos o nome de "Letramentos ocultos".

Chamaram-nos a atenção especialmente aqueles critérios ocultos de que lançavam mão não apenas os supervisores, mas também os consultores de artigos para conferências e os revisores de revistas, implicando novas demandas e situações com que os estudantes em nível de doutorado começavam a se deparar. Dessa forma, os estudantes procederam ao desenvolvimento daquelas características que, esperavam, fossem formas menos estereotipadas e mais interativas, valendo-se de aspectos mais abrangentes da prática social da escrita acadêmica e reconhecendo a importância das abordagens especificas da disciplina, mais do que as abordagens gerais. Eles, por exemplo, identificaram características ocultas como "voz", "postura" e "so what question",

Subsequentemente, escrevi um artigo para a revista do departamento, intitulada Working Papers in Educational Linguistics, que incluiu as respostas de alguns estudantes e levou em consideração as implicações para aplicações mais extensas a favor da escrita acadêmica (Street, 2009). O curso será ministrado novamente em 2015, e este artigo está na lista de 
referências bibliográficas do curso como "Academic Literacies". A investigação e as descobertas continuam seguindo o princípio da abordagem LA, e outros artigos pesquisando os avanços são esperados tanto aqui, quanto em outros países em que a referida abordagem tem sido aplicada, como, por exemplo, no Brasil.

\section{O Brasil e a abordagem LA}

O Brasil está expandindo o número de estudantes no ensino superior. Com isso, discussões e problemas similares àqueles surgidos nos Estados Unidos e no Reino Unido aplicam-se, em certa medida, a esse país. Obviamente há fatores específicos no Brasil, tais como as origens culturais e sociais de estudantes indígenas e vindos do campo (cf. Castanheira et al., a ser publicado). Começou também a despertar certo interesse o fato de que os modelos tradicionais, as habilidades de estudo e a socialização acadêmica não explicam suficientemente os problemas enfrentados por estudantes pertencentes a essas origens "não-tradicionais".

O desenvolvimento do modelo de letramento acadêmico tem implicações significativas para a forma como as instituições lidam com essas questões. A resposta institucional - típica dos Estados Unidos e do Reino Unido - de fornecer cursos extras e tutores específicos para lidarem com os "problemas" de escrita - pode não ser suficiente, especialmente quando as características culturais e sociais peculiares de "novos" estudantes são levadas em consideração. Numa universidade brasileira, por exemplo, os responsáveis pelo programa indígena começaram a se afastar do foco tradicional nos estudantes e de como "corrigi-los" para, em vez disso, levar em conta questões mais amplas sobre as relações entre tutor e estudantes e sobre as expectativas próprias dos tutores de acordo com a disciplina - uma abordagem assinalada pela perspectiva da abordagem LA.

$\mathrm{O}$ foco em projetos de letramento acadêmico, assim, desloca-se dos estudantes como "problemas" para os tutores como praticantes profundamente envolvidos no processo de auxiliar os estudantes no exercício da escrita acadêmica. Plantões e seminários interativos tornam-se elementos-chave no projeto, expondo-os à gama de modelos de escrita acadêmica e discussão de formas nas quais o modelo de letramento acadêmico pode ajudar seus estudantes. 


\section{Brian Street}

Também no Brasil, estamos começando a encontrar estudantes pesquisadores que lidam com algumas questões envolvidas em seus trabalhos de doutorado, incluindo considerar o modelo de Letramento Acadêmico e suas implicações para a prática, bem como para a pesquisa. Uma proposta de doutorado de um desses estudantes, intitulada "O Lugar de Autoria na Produção Escrita no Ensino Superior" tem como objetivo compreender as práticas de letramento numa universidade federal no Brasil. Do mesmo modo, outro estudante está fazendo o seu doutorado com o título "Academic community expectations and students' difficulties: a study about the insertion of college students in academic literacies", também envolvendo a análise de dados coletados no Brasil. Ambos os doutorandos, que também lecionam em suas respectivas universidades, usufruem de bolsas, o que lhes permite participar de atividades na King's College, trabalhando com Brian e Ursula, assim como na Open University, com Mary Lea, ministrando palestras.

Houve também algumas conferências a respeito destes temas e há planejado um colóquio específico sobre LA para 2015. Em 2012, ocorreu o 60ำ Seminário do GEL (Grupo de Estudos Linguísticos de São Paulo). Durante esse congresso, realizou-se uma mesa redonda sobre "Theories and Objects in Applied Linguistics", que incluiu uma apresentação de Theresa Lillis (Reino Unido) cujo profícuo trabalho no campo do letramento acadêmico foi citado acima. Nessa mesa redonda, Lillis apresentou o trabalho intitulado "Reframing the object: the Contribution of 'Academic Literacies' to writing and research design". Também em 2012, no Rio de Janeiro (UFRJ), Theresa Lillis foi convidada a participar do 1ํo Seminário de Escrita docente e discente, dedicado quase que exclusivamente ao tema "Letramento Acadêmico". Ela ministrou uma oficina-conferência que lidou com o tópico "Academic writing for publication: the politics of locality".

Em 2013, ocorreu a última de uma série de conferências em um evento intitulado SIGET: "Textual Genres in Multiple Levels of Human Activity" (de 03 a 06 de setembro de 2013 em Fortaleza, Ceará, Brasil). Os organizadores do evento dizem que "as perspectivas envolvidas no entendimento dos tipos de textos são tão infinitas quanto as línguas e as práticas heterogêneas; assim, é impossível não vincular os gêneros textuais a suas múltiplas esferas de atividades humanas; elas são os gêneros que efetivam a mediação entre as pessoas e que precisam de enunciação". Fez- 
se um evento intitulado "Writing Research Across Borders III" em Paris, em 2014, sendo possível reunir muitos dos pesquisadores internacionais citados acima, permitindo fazer-se sobressair o input francês a esses debates. Por exemplo, ali foi realizado um simpósio sobre "Academic Literacies and writing development", com estudos de caso do Reino Unido, da África do Sul e do Brasil.

As questões acerca do letramento acadêmico, assim, têm sido tratadas em relação aos gêneros, escrita acadêmico-universitária, redação em diversas disciplinas, socialização acadêmica e sob designações diversas em outros países - notavelmente nos Estados Unidos, no Reino Unido, no Brasil e na França. Ao mesmo tempo, questões específicas ao país e à cultura estão sendo tratadas, tais como aquelas associadas aos estudantes brasileiros indígenas ou oriundos do campo, e a relação de teorias da Retórica à escrita acadêmica na França.

\section{Rumos futuros?}

Por ora, a questão - à qual se refere este volume no Brasil - é: “como podemos aproveitar essas experiências crescentes e o trabalho teórico evidente na abordagem do letramento acadêmico para lidar com os problemas que dizem respeito a como auxiliar os tipos 'não tradicionais' de estudantes?". Além disso, não são apenas os estudantes, mas também os tutores, que - discutindo essa abordagem - podem se beneficiar ao se engajarem no modelo de letramento acadêmico, auxiliando a escrita dos estudantes nas disciplinas e trabalhando em programas para especialistas, tais como o Inglês para Fins Acadêmicos (ESP) e Inglês como Segundo Língua (ISL) etc. O livro, apropriadamente intitulado "Read, write, act and transform: an introduction to New Literacy Studies", é bastante adequado para levar adiante estas ideias, não só reconhecendo o trabalho dos New Literacy Studies (NLS), mas, também, fazendo avançar esse campo de estudos.

\section{Referências}

BLOMMAERT, J. Discourse: a critical introduction. Cambridge: CUP, 2005.

BLOMMAERT, J.; STREET, B.; TURNER, J. Academic literacies: What have we achieved and where to from here? Journal of Applied Linguistics, 4(1), 137-148, 2008.

CASTELLÓ, M.; DONAHUE, C. Eds. University writing: Selves and Texts in Academic Societies:Emerald Press: UK, 2012. 


\section{Brian Street}

CASTANHEIRA, M. L. G. C.; STREET, B. Researching academic literacies when we speak the same language, or do we? In: Special Issue of Pedagogies. Green, J. L.; Baker, W. D. Eds. (No prelo).

COFFIN, C.; DONOHUE, J. P. Eds. English for academic purposes: contributions from Systemic Functional Linguistics and Academic Literacies. In: Journal of English for Academic Purposes. Volume 11, Issue 1, Pages 1-78, 2012.

DELCAMBRE, I.; REUTER, Y. The French didactics approach to writing from elementary school to university. In: C. BAZERMAN, R.; KRUT, K.; LUNSFORD, S.; MCLEOD, S.; NULL, P.; ROGERS \& STANSELL, A. EDS. Traditions of writing research. New York/London: Routledge, 2010, p.17-30.

DELCAMBRE, I.; DONAHUE, C. University literacies: french students at a disciplinary 'threshold'? Journal of Academic Writing, 1(1), 13-28., 2011.

DONAHUE, T. Genre and disciplinary work in french didactics research. Perspectives on writing, 424, 2009.

GEE, J. P. Social Linguistics and literacies: ideology in discourse. Falmer Press: London and Philadelphia, 1990.

LANKSHEAR, C.; KNOBEL, M. New literacies: everyday practices and social learning. Open University Press: UK, 2003.

LEA, M.; STREET, B. Student writing and faculty feedback in higher education: an academic literacies approach. In: Studies in Higher Education. v.23, n.2 , 1998.

LEUNG, C. Second language academic literacies: converging understandings. In B. STREET; N. H. HORNBERGER. Eds. Encyclopedia of Language and Education. v.2. New York: Springer, 2008, p.143-161.

LEUNG, C.; STREET, B. Eds. English - a changing medium for education. Bristol: Multilingual Matters, 2012.

LEUNG, C.; STREET, B. Classroom Constructions of Language and Literacy Activity. In: Educating for Language and Literacy. Diversity Editors. Mastin Prinsloo and Christopher Stroud. Palgrave Macmillan, 2013.

ROGERS, A.; STREET, B. Literacy and development: Stories from the Field, NIACE, 2012.

RUSSELL, D.;LEA, M.; PARKER, J.; STREET, B. \& DONAHUE, T. Exploring notions of genre in 'academic literacies' and 'writing in the disciplines: approaches across countries and contexts'. In: Genre in a Changing World. Bazerman, C.; Bonini, A.; Figueiredo, D. Eds. Perspectives on Writing. Fort Collins, Colorado: The WAC Clearinghouse and Parlor Press, 2009. Disponível em: http://wac.colostate.edu/books/ genre/. Acessado em julho de 2016.

SCOTT, M.; LILLIS, T. Defining academic literacies research: Issues of epistemology, ideology and strategy. Journal of Applied Linguistics, 4, 2008, p.5-32.

STREET, B. (ed.) Literacies across educational contexts: mediating learning and teaching Caslon Publishing: Philadelphia, 2005. 
STREET, B. What's new in new literacy studies? Current Issues in Comparative Education 5(2) May 12, 2003. Disponível em: http://www.tc.columbia.edu/cice/. Acessado em Julho de 2016.

STREET, B. Hidden features of academic paper writing. In: working papers in educational linguistics. University of Pennsylvania, Spring, v.24, n.1, 2009, p.1-17.

STREET, B. The Puzzle of UK graduates and their low-level literacy (Letter to THES, 19.09.2014) In: response to an article in THES. 11 Sept., 2014.

WINGATE, U.; TRIBBLE, C. The best of both worlds? Towards an English for academic purposes/academic literacies writing pedagogy. Studies in Higher Education. 2012.

WINGATE, U. Academic literacy and student diversity: The case for inclusive practice, Multilingual Matters, London, 2015. 